\title{
Five Kinds of Perspectives on Legal Institutions
}

CORRADO ROVERSI

\section{DRAFT - Please do not quote without permission}

\section{Introduction: Hart on Concepts and Points of View}

At the end of Chapter 5 of The Concept of Law, titled "Law as the Union of Primary and Secondary Rules", Hart writes:

If we stand back and consider the structure which has resulted from the combination of primary rules of obligation with the secondary rules of recognition, change and adjudication, it is plain that we have here not only the heart of a legal system, but a most powerful tool for the analysis of much that has puzzled both the jurist and the political theorist. [...] Most of the obscurities and distortions surrounding legal and political concepts arise from the fact that these essentially involve reference to what we have called the internal point of view: the view of those who do not merely record and predict behaviour conforming to rules, but use the rules as standards for the appraisal of their own and others' behaviour. This requires more detailed attention in the analysis of legal and political concepts than it has usually received. Under the simple regime of primary rules the internal point of view is manifested in its simplest form, in the use of those rules as the basis of criticism, and as the justification of demands for conformity, social pressure, and punishment. [...] With the addition to the system of secondary rules, the range of what is said and done from the internal point of view is much extended and diversified. With this extension comes a whole set of new concepts and they demand a reference to the internal point of view for their analysis. These include the notions of legislation, jurisdiction, 
validity, and, generally, of legal powers, private and public. (Hart, 2012 (1st ed. 1961), p. 98-9)

It emerges clearly from this passage that Hart considers his distinction between primary and secondary rules, as well as his concept of internal point of view, as useful tools for explaining a specific kind of conceptual knowledge typically shown by professionals in the practice of law. Hence, in Hart's view, an explanation of legal concepts calls for an explanation of a specific perspective over the law, namely, the "internal" perspective of a participant who accepts (in a properly qualified sense of "acceptance") the normative structure of the legal system.

Some authors, however, have insisted on the fact that the use of legal concepts in the context of seemingly normative sentences, and thus the formulation of "internal statements" in Hart's sense, is not sufficient to qualify as internal the point of view of the relevant speaker: As a consequence, the internal point of view is only one among the possible perspectives in which statements containing normative vocabulary are made. Joseph Raz, for example, has famously argued that some kind of statements which seem internal are in reality "detached", in the sense of being statements "from the point of view of the legal system" without necessarily implying a positive endorsement of that system (see (Raz, 1999 (1975), p. 170-7); (Raz, 1980 (1st ed. 1970)), p. 234-8); for a criticism of this idea, see (Toh, 2007)). Conversely, Stephen Perry has maintained that even Holmes's "bad man", which in Hart's view epitomizes the external point of view, could instead be interpreted as internal, because even the bad man knows the normative structure of the legal system and considers that structure as reason-giving: Only, he treats such reasons as prudential and not normative (see (Perry, 2000, p. 164-6)). Hence, Hart's internal point of view seems to be unable to account for the whole of the linguistic practice in which legal concepts appear: In the end, it has difficulties both in including (as in the case of detached legal statements) and in excluding (as in the case of the "bad man") specific usages of legal concepts. Eventually the idea of explaining the semantics and pragmatics of the normative vocabulary typical of a given legal system by means of a peculiarly "internal" perspective of the speaker finds its limit in the indeterminacy of that perspective.

However, by loosening the tie between concepts and perspective we can perhaps take up Hart's project and further specify it. We can say that the appeal to legal concepts in normative statements is typically linked with a given perspective without requiring it to be 
necessarily so, and we can proceed in formulating further distinctions among kinds of legal concepts in order to identify different perspectives over the law, all in a more or less strict relation with the internal point of view. This would make the very idea of internal (and external) point of view and of internal (and external) statements significantly less indeterminate.

This paper is meant to be a step in this direction. In what follows, I will distinguish between five kinds of concepts relevant for an institution and will show that, when applied to law, this distinction makes it possible to identify five different perspectives on legal phenomena, perspectives that seem to elaborate significantly Hart's distinction between internal and external point of view and to provide further elements for the debate that has ensued from that distinction. The structure of the paper is as follows. In Section 2 I discuss institutional concepts, clarifying in what sense they can be interpreted as concepts constituted by rules and showing that they typically correspond to a structural perspective over a given legal system. In Section 3 I deal with meta-institutional concepts, distinguishing between teleological and axiological meta-institutional concepts and showing how these two kinds of concepts can be used when adopting respectively a teleological and axiological perspective over the legal system. In Section 4 I introduce the category of para-institutional concepts, distinguishing between praxeological and idiomatical para-institutional concepts and showing how they can be used when adopting respectively a strategic and sociological perspective. In Section 5 I put the perspectives thus obtained in relation with Hart's distinction between internal and external point of view, and I show how they can specify and enrich that distinction. Finally, in Section 6 I draw some conclusions.

\section{Structural Perspective}

In this paper, I will often speak of institutions, institutional facts, and institutional practices, and thus it is necessary to avoid a confusion since the beginning. This paper deals with legal institutions in particular, but in general I adopt a very broad notion of "institution". This notion is borrowed from social ontology, and in particular from John Searle's theory. Searle assumes a notion of institution which includes phenomena that would not be classified as institutional according to standard linguistic usage. For example, the game of chess is an 
institution in Searle's sense, but not so according to the ordinary meaning of this word. Let me explain in further detail his view.

In Making the Social World, Searle distinguishes between three different types of institutional facts (Searle, 2010, p. 94-8). The first type he calls "creation of an institutional fact without an institution" (Searle, 2010, p. 94): Here, members of a community simply assign normative consequences (connected with what Searle calls "status functions") to a given entity by virtue of collective acceptance, as in the case of a line of stones which is collectively recognized as a boundary. While there is a rule here concerning the attribution of normative consequences to a concrete and specific entity, there is no standard connection between entities of a given kind and one or more normative consequences: What matters is the individual entity to which normative consequences are attributed. But, in Searle's view, it is the standard and recurrent connection between kinds of entities and normative consequences - so to say, the apposition of a universal quantifier on a given status-function attribution - that which makes an institution, and for this reason institutional facts of this first type are not, strictly speaking, institutions.

This standard and recurrent connection, and thus the presence of a full-fledged institution, is only typical of the second type of institutional facts envisaged by Searle. Here we have status-function attributions - and hence, attributions of normative consequences - on the basis of constitutive rules in the form " $\mathrm{X}$ counts as $\mathrm{Y}$ in context $\mathrm{C}$ ", as when a community "evolve a standard procedure for selecting the king" (Searle, 2010, p. 96). The crucial difference with respect to institutional facts of the first kind is that the rule here has not to do with a specific individual recognized as the king, but rather with a procedure on which basis every king can be selected on every occasion.

I will skip the details concerning Searle's third type of institutional fact, because for my purpose it does not differ significantly from the second (it has to do with constitutive rules that create institutional facts out of simple declarations, as in the case of corporations and other immaterial institutional entities). What I would like to note instead is that, of these three types, only the second and the third, in which constitutive rules occur, entail the creation of new concepts. Searle's institutional facts of the first type, in fact, simply involve the attribution of normative consequences and import to an individual entity, while both the concept of these consequences and of the "brute" entity can very well be created independently from that particular institutional fact. When, for example, we assign by 
declaration the status of boundary to a given line of stones, we presuppose the concept of boundary rather than constituting it: We know what a boundary is, we know what it means to be a boundary, and we assign this status to the line of stones. Not so when we have to do with constitutive rules. Searle clarifies that constitutive rules are standards for the attribution of status functions, standards that specify under which conditions (and to which kind of entity, act, fact, or event) a given status function-and hence, again, normative consequences— can be attributed: This is the role of the formula " $\mathrm{X}$ counts as $\mathrm{Y}$ in context C", that specifies under which condition $\mathrm{X}$ a give status $\mathrm{Y}$ can be applied. Now, given that status $\mathrm{Y}$ is in its own turn connected with a status function, and this function is connected with normative consequences ("deontic powers", in Searle's own terminology), it is better to slightly modify Searle's formula and specify the full constitutive rule of a given institutional fact with the normative element, for example stating " $\mathrm{X}$ counts as $\mathrm{Y}$, and $\mathrm{Y}$ has normative import $Z$, in context C".

This formula creates a new concept of $\mathrm{Y}$ because it fully specifies Ys' conditions of identity: In particular, two Ys are the same $\mathrm{Y}$ if they correspond to the same $\mathrm{X}$ and entail the same status function $\mathrm{Z}$. We have to do here with a standard procedure for selecting Ys in the world and for attributing them an institutional meaning: Thus, even if the concepts of $Z$ (the normative consequences) and $\mathrm{X}$ (the brute element) are already existing, nonetheless here a new concept arises, namely, that of $\mathrm{Y}$.

Under this definition, it should now be clear how Searle's conception of institution is extremely over-inclusive. Consider again the game of chess, which ordinarily we would not be inclined to consider as an institution. Chess is instead a typical example of an institution in Searle's sense, because it is a system of rule-constituted concepts. Terms such as king, queen, bishop and the like have in fact a distinctive chess-relative meaning even though they certainly have an ordinary and completely different meaning - and the system also includes concepts ("checkmate", for example) which are introduced by means of neologisms. The constitutive rules of chess create these concepts by defining both their conditions of fulfillment and the "deontic power" or normative consequences associated with them (in the

1 This reformulation of Searle's constitutive rules has been discussed at length by Frank Hindriks and before him by Neil MacCormick: see (Hindriks, 2005), (Hindriks, 2009), (MacCormick, 1986), (MacCormick, 1998). 
case of chess pieces, the rules set forth the pieces' starting place on the chessboard, the discipline of their movement, and their power to take other pieces and possibly to attack the king).

One could object at this point that, taking into account Searle's own example of institutions of the second type (that of a standard procedure for selecting a king), there is no correspondence between constitutive rules and the creation of new concepts. In fact, one would say that we already have the concept of a king, and that with this concept we simply do the same thing that we do in the case of institutional facts of the first type: We attribute status functions and normative consequences without any need to create new concepts. ${ }^{2}$ This is not so, however. In fact, if we set forth a constitutive rule stating that the the king $(\mathrm{Y})$ is a person selected in this and that way $(\mathrm{X})$ and having this and that power and/or obligations $(Z)$, in this way we create a new concept of "king" relative to our institutional setting - "technical" concept, so to say, even though the term king has a nontechnical meaning in ordinary language. This is the main feature of what I will call institutional concepts, namely, that constitutive rules are the necessary and sufficient conditions for their existence because they create them. And, as said, this presupposes an extremely broad sense of "institutional", because in this regard the State's king is not so much different from the king in chess.

Law has an abundance of institutional concepts. When we speak of "marriage" in a legal sense, for example, we deal with a technical concept that is constituted by rules (in Italy, Art. 79ff. of the Civil Code), a concept which certainly has affinities and relations with its ordinary counterpart but which nevertheless does not coincide with it. Marriage in the legal sense is something different, and more specific, than marriage in a social and looser sense, because it has to do with rights and obligations that find their place in the legal system and thus have an impact on other norms of that system. Or consider the concept of "age of majority": Art. 2 of the Italian Civil Code states that a person attains age of majority at the

2 The reader should note here that I am not maintaining that with institutional facts of the first type we never create new institutional concepts. We can certainly have the concept of a specific and non-repeatable concrete institutional entity, as with the territory of the Italian State, for example. What I am arguing here is that constitutive rules create new institutional concepts, not that they are the only way to create those concepts - they are a sufficient, and I would add quite typical, but not necessary condition. 
age of 18 , and that with age of majority a person acquires full legal capacity. This is a clear case of constitutive rule: "In the Italian legal system, the age of $18(\mathrm{X})$ counts as $(\mathrm{Y})$ the age of majority, and age of majority entails (Z) legal capacity". Art. 2 sets down both the conditions for attainment of legal majority and its normative consequences, thus creating the relative Italian legal concept: Therefore, the strictly technical legal meaning of age of majority in the Italian legal system is constituted by rules. ${ }^{3}$

As already mentioned at the beginning of this paper, these legal institutional concepts - that is, concepts constituted by the rules of a given legal system - hold a strict correspondence with the basic perspective that legal scholars and practitioners must be able to adopt over facts, acts and events. The following, well-known passage from Kelsen's Reine Rechtslebre shows the point very well:

If one analyses a parliamentary enactment, say, or an administrative act, a judicial decision, a private law transaction, a delict—all of which are referred to as [belonging to the] law-one can distinguish two elements. There is an act perceptible to the senses, taking place in time and space, an external event, usually an instance of human behavior. And there is a specific meaning, a sense that is, so to speak, immanent in or attached to the act or event. People assemble in a hall, they given speeches, some rise, others remain seated - this is the external event. Its meaning: that a statute is enacted. Or, a man dressed in robes says certain words from a platform, addressing someone standing before him. This external event has as its meaning a judicial decision. A merchant writes a certain letter to another merchant, who writes back in reply. This means they have entered into a contract. An individual brings about the death of another, and this means, legally speaking, murder. [...E]xternal circumstances are always a part of nature, for they are events

${ }^{3}$ For obvious limits of space, I will not consider in this paper Alf Ross's theory of legal concepts as a connection between conditions and normative consequences (see (Ross 1957 (1951)), a theory that can be taken to undermine the relevance of constitutive rules in determining the semantics of legal concepts. I criticize this theory at length in (Roversi 2012, chap. 3). It is important to note, however, that even if one accepts Ross's theory, constitutive rules can nevertheless be admitted as explanatory tools for the analysis of legal concepts, without endowing them with any ontological role. In this sense, constitutive rules can be considered simply as a more elaborate way to analyze the connection between conditions and normative consequences envisaged by Ross. On the distinction between an analytic and an ontological use of constitutive rules, see also (Rotolo and Roversi 2013, 165-8). 
perceptible to the senses, taking place in time and space; and, as a part of nature, they are governed by causal laws. As elements of the system of nature, those events as such are not objects of specifically legal cognition, and thus are not legal in character at all: What makes such an event a legal (or an illegal) act is not facticity, not its being natural, that is, governed by causal laws and included in the system of nature. Rather, what makes such an event a legal act is its meaning, the objective sense that attaches to the act. The specifically legal sense of the event in question, its own peculiarly legal meaning, comes by way of a norm whose content refers to the event and confers legal meaning on it; the act can be interpreted, then, according to this norm. The norm functions as a scheme of interpretation. [...] The aforementioned exchange of letters means that a contract has been concluded, and it has this meaning solely because these circumstances fall under certain provisions of the civil code. That an assembly of people is a parliament, and that the result of their activity is a statute (in other words, that these events have this 'meaning'), says simply that the material facts as a whole correspond to certain provisions of the constitution. That is, the content of an actual event corresponds to the content of a given norm. (Kelsen, 1992 (1934), p. 8-10)

Which kind of perspective is that described by Kelsen in this famous passage? It is a purely structural perspective, according to which we simply qualify facts and acts in legal terms. This is the perspective in which we say, for example, "a legal transaction has occurred here", or "the assembly voted", or again "that boy has already attained the age of majority": Legal assertions having as their content the subsistence of some rule-defined fact, act, event or property to which the legal system attach normative consequences. From this perspective we can also draw normative statements as conclusions from factual statements regarding the correct instantiation of an institutional fact as premises, as when we say "that boy has already attained the age of majority and hence acquired full legal capacity".

What I would like to show now, however, is that it would be naïve to think (as one could be tempted to do in the light of a narrow interpretation of Searle's theory of institutions) that the whole set of concepts relevant for law coincide with that of institutional ruleconstituted concepts, so that the only relevant legal perspective would be structural. There are other kinds of concepts which are undoubtedly relevant but which are not strictly speaking constituted by rules, and hence are not institutional concepts in the sense above introduced. The fact that these concepts are relevant for institutions while not being 
constituted by rules shows that other institutional perspectives can be important apart from the purely structural one. Let me explain how this happen.

\section{The Axiological and the Teleological Perspective}

Consider again the example of chess. When we play a match of chess, we try to checkmate our opponent by moving pieces in a way he does not expect, thus behaving in the light of several different institutional concepts, thinking about our actual possibility to realize them and trying to make good use of their normative import in the match. But a time comes when we, or our opponent, say "I have won". This is an extremely relevant statement for chess players, one that immediately requires verification. But what is this concept of "victory" which emerges in our practice of chess?

I think it should be immediately clear that victory is not a rule-constituted institutional concept on the same level as, for example, "castling" or "checkmate". ${ }^{4}$ While the conditions of fulfillment of victory in a chess match are determined by rules because victory is the normative consequence of checkmate, whose concept is constituted by the rules of chess, the import of victory-what it means to win in chess - is not constituted by the rules of chess. This question, in fact, has not so much to do with chess but rather with the broader practice of competitive game-playing of which the game of chess is an instance. What it means to win in chess is something we know if we are acquainted with this broader practice in general, and hence with chess as an instance of a game, rather than in particular with chess as a system of constitutive rules. ${ }^{5}$

${ }^{4}$ This has also been noted by Amedeo G. Conte (Conte, 1995 (1st ed. 1993), p. 530) and then by Giuseppe Lorini (Lorini, 2003, p. 299).

5 A note on this concept of "broader (social or legal) practice", which I will be using extensively in the rest of this paper. The distinction between an institution conceived as a system of constitutive rules, on the one hand, and the broader social meaning of that institutional activity, on the other, has been introduced for the first time by Hubert Schwyzer in discussing Searle's concept of "constitutive rules" in terms of Wittgenstein's concept of "grammar": see Schwyzer 1969. The same distinction has been discussed at length, and with particular reference to law, by Giuseppe Lorini (as a distinction between an institutional praxis and a social practice: see Lorini 2000, 263ff.) and more recently by Andrei Marmor (in terms of his dichotomy between "surface" and "deep" conventions: 
But victory has a peculiar relation with this system of constitutive rules. In fact, the constitutive rules of chess must specify conditions of victory exactly because chess is a competitive game, otherwise we would not be able to understand in what sense it is competitive. Hence, it is the general meaning of chess as an instance of competitive game that which requires the inclusion of victory among its relevant concepts, so that the fundamental import of the concept of victory depends not on constitutive rules but on the general meaning of chess. This is why I call concepts like victory meta-institutional concepts: Because their relevance for the institution is entailed not by constitutive rules, as in the case of other institutional concepts, but on the overall meaning of the system of rules as an instance of a given social practice. ${ }^{6}$ This is a matter of conceptual entailment, like in the case of other institutional concepts: But while the content of institutional concepts is linked with constitutive rules, the content of meta-institutional concepts is connected with the general practice in which those constitutive rules play their role-in our example, the concept of competitive playing entails the relevance of victory. Given that victory is the objective of the game, I will call meta-institutional concepts like victory "teleological". Teleological metainstitutional concepts have to do with the distinctive outcome(s) of the general practice within which we perform institutional acts of a given kind. ${ }^{7}$

Not all meta-institutional concepts are teleological, however: There are others not necessarily connected with the typical outcome of the practice. Consider, in chess, the example of cheating: During a match, I surreptitiuosly swap the black king with the black queen, but you catch me and cry out, "You are cheating!". It seems this is a relevant statement in our practice-indeed, in this case I should defend myself or quit the game dishonoured. But, as in the case of victory, the concept of cheating is not constituted by the

see Marmor 2007, 2009). In all these cases the basic idea is that, in order to assess the conceptual content of an institutional activity, the system of its constitutive rules is not sufficient: It is also necessary to understand the activity's core social meaning, and hence to grasp the concept of the broader (and "deeper") social practice of which that institutional activity is an instance.

${ }^{6}$ The expression meta-institutional, along with its concept, is not mine but can be found in a wonderful paper by Dolores Miller (Miller, 1981), in which she discusses the example of victory in competitive game-playing in analogy with the role that the concept of obligations plays in Searle's (1969, p. 63ff.) theory of the "essential rules" of speech acts. 
rules of chess, rather being connected with some features of the general game-playing practice. Games, even competitive games, typically involve a cooperative attitude in players according to which they together accept to abide by the game's rules, and cheating is a violation of this attitude, one which is sanctioned not because of the game's constitutive rules but because of the general concept of game-playing. There is, however, a crucial difference between victory and cheating. While constitutive rules determine how to win in chess, they clearly do not determine how to cheat: You can cheat in many different ways, and none of these is set down in a rulebook. Thus, constitutive rules determine the conditions of fulfilment of cheating in a more indirect way than in the case of victory: By determining how to play, they are fundamental in determining how to cheat as well-you cannot cheat if not by knowing the constitutive rules of chess, and you must at least simulate a rule-following behaviour in order to cheat properly. ${ }^{8}$

Cheating is thus linked with the general social practice of competitive game playing, and constitutive rules only determine its conditions of performance for each game. As we have seen, these are the main features of meta-institutional concepts. However, cheating is not a teleological meta-institutional concept like victory. Instead, given that game-playing is connected with a cooperative attitude, and given that this kind of cooperation is connected with typical social values such as honest behavior and sportsmanship, cheating is typically a value term denoting a kind of wrong and dishonest attitude. I will call meta-institutional concepts such as cheating "axiological": Axiological meta-institutional concepts have to do with the main values and principles that are connected with the general social practice in which constitutive rules play their role, and thus emerge when we somehow evaluate the behavior of agents engaged in institutional practices.

Teleological and axiological meta-institutional concepts are extremely relevant for understanding institutions. Consider another passage from Searle's Making the Social World:

The system of statements making, ownership of property, and promising function only on the presupposition that, other things being equal, one can reasonably assume that one's own utterances and the utterances of other people are attempts at stating the truth; that property ownership confers rights and duties on the owner; that the making of a promise, other things being equal, creates a reason for the agent to keep a promise. [...] Only to the

8 To my knowledge, so far the best treatment of the problematic relation between cheating and the constitutive rules of a game has been made by Amedeo G. Conte: see (Conte, 2003). 
free agents do such systems make any sense, but precisely for free agents such systems are necessary. A system which did not have this capacity to create desire-independent reasons for action would collapse. (Searle, 2010, p. 142)

Searle's example of property in this passage is particularly relevant for our purposes because it is drawn from the legal domain. In Searle's view, the main and crucial reason to accept and engage in the institution of property is that this institution-and institutions in general-can give desire-independent reasons for action connected with the status function that are attributed to institutional elements: It can, for example, give people reasons to stay out of my house even if they would like to occupy it.

I agree with Searle that one typically engages with the legal institution of property because of its capacity to confer rights and duties. However, it is crucial to understand here that, when Searle says "property ownership confers rights and duties on the owner", the rule-constituted concept is that of property ownership, not those of rights and duties. "Right" and "duty" are general concepts through which law specifies typical legal outcomes: They represent in a sense the "grammar" of law, not only the peculiar outcome of property ownership. Hence, the concepts of right and duty are not on the same level as that of property ownership, because the latter is a simple institutional rule-constituted concept, whereas the former two are not constituted by the rules of a specific legal system: They are not institutional but rather teleological meta-institutional concepts.

Further, in the above-quoted passage Searle seems to miss at least one crucial reason why people can find that the institution of property provides us with desire-independent reasons for action: In short, they can think that this institution is just. Justice can give people desireindependent reasons for action even if they do not aim at obtaining the deontic powers connected with institutional elements: I can, for example, embrace the institution of property for reasons of justice only, even if I do not plan to own anything. But, clearly, the concept of justice is not constituted by the rules of property ownership: It is the value concept typically connected with law in general and not with a particular institution in a given legal system. Hence, with regard to a given legal system, that of justice is a metainstitutional rather than institutional concept, and specifically it is an axiological metainstitutional concept used in evaluative statements.

This complex intertwining of legal institutional and meta-institutional concepts can be further exemplified by appealing to the example of norm-enacting procedures. Legal systems 
typically set down the main procedures by which to enact valid norms, and these procedures can be accounted for in terms of constitutive rules. In Italy, for example, the Parliament can enact valid statutes by fulfilling specific procedural steps: But the term for these statutes, namely, legge, is a technical term in the Italian legal system, because there are other sources of law which are not strictly speaking leggi (see Art. 1 of the Italian Civil Code). Hence, one can reconstruct this institutional framework by defining statutes in terms of constitutive rules, for example by stating that a text approved by both chambers of the Italian Parliament under a given procedure $(\mathrm{X})$ counts as a legge $(\mathrm{Y})$, and the institutional import of a legge is that of determining one or more legally valid norms (Z). Let us assume Kelsen's conception according to which valid can be made to mean, among others things, legally binding, or obligatory (see Kelsen 1992 (1934), 12-3; 55ff.). It is clear that "validity" in this sense is nothing else than the fundamental concept of all kinds of norms-enactment procedures in law and not a simple rule-constituted concept relative to a specific legal system: All legal norms are produced to be "valid" in the sense of "binding within a given community". Thus, while that of legge is an institutional rule-constituted concept because it is relative to the Italian legal system and its constitutive rules, the concept of "legal validity" is a teleological meta-institutional concept which represents the typical outcome of legal normenacting procedures in general.

Moreover, apart from being "valid" in this sense, statutes can also be distinctively just or unjust, and norm-enacting procedures can be evaluated in the light of their capacity to realize substantive moral and political values such as democracy, for example. As in the example of property already discussed, however, when I make these evaluations - when I say, for example, that a given Italian legge is unjust, or that the whole system of normenacting procedures in Italy are not democratic in full-I do not compare an instance of institutional concept with another kind of institutional, rule-constituted fact internal to the Italian legal system: Rather, I consider to what extent that element of this peculiar legal system is coherent with some fundamental principle or value of law more generally considered, and in so doing I take into account, along with institutional rule-constituted concepts, axiological meta-institutional legal concepts relevant for many different ruleconstituted institutions traceable to the general legal practice of norm enacting.

In the light of these examples, it should be clear that teleological and axiological metainstitutional concepts correspond to different perspectives on legal institutions. Basically, a 
teleological perspective calls into questions the institution's essential point, objective or aim, while the axiological perspective takes into consideration its basic values and principles — and in both cases judgments are formulated by considering the institution as an instance of a more general legal practice. From a teleological perspective, I can make statements such as "The overall purpose of the practice of norm-enactment is to produce valid norms", while the axiological typically involves statements such as "In its current legal form, the institution of property is just/unjust for this or that reason".

A crucial point is that, even though these perspectives typically requires considering the institution as a whole $—$ with particular reference to the more general legal practice in which that institution is inscribed - they also have a distinctive feedback on several statements that can be formulated in regard with specific legal acts or facts, making it possible to see different kinds of legal mistakes that cannot be traced simply to structural problems. Let me show how this happens. Consider a legge (again, a particular kind of statute in the Italian legal system) which is enacted in a formally correct way but which prescribes an impossible course of action. Here, the problem does not emerge from a purely structural perspective, because in the Italian constitution there is no provision stating that a legge must prescribe only factually possible courses of action. But this is a trivial legal mistake nevertheless, and the reason emerges from the teleological perspective that qualifies that statute from the point of view of the general objective of the norm-enacting practice. If statutes are enacted in order to create binding norms, then a statute that cannot bind anyone is mistaken even if formally perfect. Thus, there is something paradoxical and self-defeating in the enactment of norms that for some reason cannot be binding, even if that instance of norm enacting is performed in perfect accordance with the constitutive rules of the legal system under consideration. This shows that some legal mistakes can emerge only if we adopt a teleological point of view on legal institutions, and hence do not limit ourselves to a purely structural one.

The second example is not mine but drawn from Robert Alexy's "argument from correctness" (see Alexy 2002, 35ff.). According to Alexy, an act of constitutional normenactment like " $\mathrm{X}$ is a sovereign, federal, and unjust republic" is a peculiar kind of performative contradiction because it patently conflicts with the claim to correctness and justice implicitly raised by all acts of legal norm-enactment (see Alexy 2002, 38). Even though I have my doubts concerning Alexy's argument-in particular, I am not sure 
whether the above-mentioned act of norm-enactment is indeed a genuine performative contradiction, nor whether the claim-to-correctness thesis can be derived from it as a general thesis about law-I agree with him that there is something conceptually wrong in that constitutional norm. More importantly for our purposes, it seems evident that mistakes of that kind can emerge only if we adopt a non-purely-structural perspective over the act of norm-enactment: In fact, the problem here is not that the procedures for enacting a constitutional norm have not been followed correctly, but rather than something wrong happens even if we are following those procedures correctly. Hence, in order to assess this problem or at least understand it, we must see how that act of norm-enactment is inscribed in a general practice with definite values, and how those values are conceptually interconnected with the inner structure of that practice: That is, we must adopt an axiological perspective on law distinct from the purely structural one.

One would be tempted to consider the teleological and axiological perspectives as second-order perspectives with respect to the structural one, because the question of aims, purposes and values underlying a legal institution seems to arise only when structural questions are already settled. Such a conclusion would be doubtful, however. On the one hand, it can happen in law that teleological considerations overcome structural ones, as when a given legal act is considered as if it were correctly performed, even if it is not, for the sole purpose of preserving its intended purpose. In Italian private law, for example, under certain circumstances a contract which cannot have normative consequences for structural reasons can be "transformed" so as to have them (see Art. 1424 of the Italian Civil Code), and more in general all the clauses of a contract must be interpreted in a way that is structurally "charitable" for teleological reasons (that is, the interpretation according to which a contract's clauses can have legal effects must be privileged: see Art. 1367 of the Italian Civil Code). ${ }^{9}$ Further, and on the other hand, it is very difficult to sharply distinguish structural and axiological considerations in contemporary constitutional states: Indeed, one of the main points of contemporary legal theories on the connection between law and morality is precisely that of blurring this distinction. It would therefore be mistaken to

\footnotetext{
${ }^{9}$ This the so-called "principle of conservation" (principio di conservazione) of legal acts, which to my knowledge has applications not only in private law but also in administrative and procedural law, and which has equivalents not only in French and German law (actually it traces back to the Roman brocard "magis valeat quam pereal"), but also in the common-law tradition.
} 
attribute in principle logical priority to the structural perspective over a teleological or axiological one: They are on the same "level", so to say, and all have to do with the concept of a given legal institution. When we consider an institution structurally, our focus is on the complex web of its internal technical concepts; when we consider it teleologically, our focus is on its purpose as a whole; and finally, when we consider that institution axiologically, our focus is on the values and principles underlying it. Among these different approaches none seems to have necessary logical priority: In the end, which perspective should prevail is a matter of the overall conception of law we adopt.

Teleological and axiological considerations about law are often intertwined in a peculiar way. First, at least on a very general level, all legal institutions inscribed in contemporary constitutional legal systems can be interpreted as having among their objectives that of fostering - or at least not conflicting with - the more or less substantial axiological content of the constitution to which they are subordinate, thus giving a distinctive teleological qualification to this substantial moral content. Further, particular conceptions of law can give a fundamental axiological value to the overall purpose of legal systems, thus endowing the very practice of law in all its aspects with an axiological meaning. The necessity of these kinds of connection should be-and have been-argued independently and, again, arguments of this kind depend on the general conception of law we intend to adopt.

There is a final complexity concerning what I have called above "teleological metainstitutional concepts" and "teleological perspective". An institution can be interpreted teleologically in at least two different senses: On the one hand, it can be interpreted as a set of acts, facts, and roles teleologically oriented towards a given goal or objective; on the other hand, it can be seen as a social practice as a whole, which has a more or less definite social purpose and thus plays a role in a given conception of society. This double role of teleology can be exemplified again by appealing to games. In a game, while victory can be conceived as the objective of the acts of players, it is not properly speaking the objective of the whole practice of the game, because this inevitably calls into question the dimension of fun as a fundamental objective: Under normal circumstances we play for fun, even if we compete one against the other in order to win. Thus, we could say that in competitive games victory is the distinctive objective of competitition but only in the general recreative environment that has fun as its main objective (see in this regard, among others, (Kolnai, 1966)). Law is not different in this regard. The institutional structure concerning norm-enacting in the 
Italian legal system, for example, certainly has as its main objective the enactment of valid norms, but it also has a social purpose, namely, that of guaranteeing a significant degree of democratic control over the production of authoritative and enforced social norms. Let me call these two dimensions of a teleological perspective over the law "normative" and "social". Both the normative and the social are aspects of a teleological perspective over the institution of norm enacting, but only the first calls directly into question "validity" as a meta-institutional concept. As we have seen, in fact, the reference to validity in the socialteleological dimension is only indirect, validity being certainly the way in which we realize the social purpose of strictly regulating the production of authoritative social norms, but being the normative way, namely, specified in terms of the internal functioning and structure of the legal system. The overall system of institutional fact, acts, and roles teleologically ordained toward the enactment of valid norms in its own turn has a specific social purpose: The first is the internal, normative, teleology of norm-enactment, whereas the second is the external, social one.

\section{The Strategic and the Sociological Perspective}

Up to now, I have treated two kinds of concepts (meta-institutional teleological and axiological concepts) which, despite their obvious relevance for legal and institutional reality, are neither constituted by the rules of a specific institution nor are specific of that institution, rather being typical of more general social practices in which rule-constituted institutions are embedded. Now I will instead discuss two other kinds of concepts which, while specific to rule-constituted institutions and hence different from meta-institutional concepts in this regard, are not constituted by the institutions' constitutive rules just like meta-institutional concepts. To show how this is possible, and keeping in mind my broad concept of institution as discussed above, I will start again from the example of chess. Consider the following statements:

The King's Indian Attack (KIA), also known as the Barcza System (after Gedeon Barcza), is a chess opening system for White, most notably used by Bobby Fischer. [...] The KIA is often used against the semi-open defences where Black responds asymmetrically to e4, such as in the French Defence, Sicilian Defence, or Caro-Kann Defence. Yet it can also be played against Black's more common closed defenses, usually through a move order that begins with 1.Nf3 and a later fianchetto of the white-square bishop. For this reason, transpositions to the Réti 
Opening, Catalan Opening, English opening or even the Nimzo-Larsen Attack (after b3 and Bb2) are not uncommon. ${ }^{10}$

We have here a list of several different terms which denote kinds of attacks, defences, and openings in chess. As is well-known, statements including similar concepts are not uncommon but rather normal in chess theory: Indeed, in this game you can make several different kinds of attacks and defences, which are formalized through distinct concepts. These concepts are not institutional: In fact, they are not constituted by the rules of chess but rather denote different ways to use the institutional rule-constituted elements of chess. This does not mean, however, that these concepts are meta-institutional. The main reason that prevents them to be qualified as meta-institutional is that they do not depend on the features of the general game-playing practice but rather on specific features of chess: Trivially enough, you cannot perform a King's Indian Attack in another game. Hence, as anticipated, we have here concepts that, while not being constituted by the rules of an institution, are peculiar to that institution, namely, emerge from the institution's specific rule-constituted features.

I will call concepts of this kind para-institutional concepts, using the prefix para- in the same sense as it is used in terms such as paramedic, paralegal, or paralanguage, namely, as qualifying objects which are in a sense attached to more fundamental entities and which therefore "come after" these entities, thus being subordinate to them. The example of paralanguage can be particularly useful to explain what I intend here. Paralinguistics studies the nonstrictly-formal linguistic factors that usually accompany utterances, such as volume or intonation, but all these factors come in a sense necessarily attached to utterances: Thus, linguistic utterances are the fundamental layer over which paralinguistic features can apply. This is the same with para-institutional concepts: They are used as part of descriptive sentences which already take for granted the instantiation of one or more institutional element. When, for example, I say that "Kasparov has performed a King's Indian Attack", the truth conditions of this sentence include the truth of other descriptive sentences such as "Kasparov has moved the knight", "Kasparov has castled", "Kasparov has moved two

10 The passage is drawn from Wikipedia: http://en.wikipedia.org/wiki/King $\% 27 \mathrm{~s}$ Indian_Attack. Italics are added. 
pawns", etc., and these last sentences are made from a structural perspective in that they involve only institutional, rule-constituted concepts.

In a game, para-institutional concepts do not necessarily denote strategies or performances, as in the case of attacks or defences. They can also denote peculiar features of the actual practice of a game, as distinguished by its rule-constituted structural features. Consider in chess, for example, the case of the so-called "first-move advantage", namely, the white players' typical advantage due to the fact that he moves first. The concept of "firstmove advantage" is not constituted by the rules of chess but has to do with how chess turns out to be when it is actually played: It denotes a typical feature of chess in practice, distinct from the typical features set down by constitutive rules on paper. Just like the concepts which denote the different kinds of attacks elaborated in chess theory, that of "first-move advantage" depends on constitutive rules - it could not have any clear meaning if those rules did not define the constitutive elements of chess - but is not constituted by those rules: It denotes a sort of subordinate feature of chess entailed by its constitutive features. Thus, the concept of "first-move advantage" is a para-institutional concept. However, the first-move advantage is not a strategy or performance you can make with institutional elements, like attacks or defences: It is rather a fact about chess, something which typically happens and not something which can be done. In order to capture this difference, I will distinguish between act-describing, or praxeological, para-institutional concepts and fact-describing, or idiomatical, para-institutional concepts: Praxeological para-institutional concepts denote kinds of actions, strategies or performance we can put into practice by instantiating one or more institutional concepts, while idiomatical para-institutional concepts denote peculiar features that emerge from the actual practice (as opposed to the rule-constituted structure) of that institution. ${ }^{11}$

Searle's theory is again helpful here. In Making The Social World, in fact, Searle has treated the problem of idiomatical para-institutional phenomena under the label "systematic fallouts", and has underscored several crucial properties of these phenomena, the most important being that while institutional phenomena depends (in his theory) on collective

${ }^{11}$ I use here the expression idiomatical as a neologism, thus avoiding any relation with the obsolete English equivalent of idiomatic. I use this term because it traces back to the Hellenistic Greek word idioma, which means "peculiar feature". 
acceptance, idiomatical para-institutional phenomena - systematic fallouts- do not depend on acceptance: They are "intentionality-independent facts about intentionality-relative phenomena" (Searle, 2010, p. 117). ${ }^{12}$ Further, Searle notes that, while institutional elements typically have "deontic powers" or normative consequences, systematic fallouts do not have such consequences. Thus, systematic fallouts depend on "ground-floor institutional facts" and carry no distinctive deontology, to the point that participants in a given institutional practice can very well be unaware of them. Searle makes in this regard an example regarding baseball which is very similar to my example of "first-move advantage" in chess:

To take a trivial example, it has been discovered in baseball that, statistically, left-handed batters do better against right-handed pitchers, and right-handed batters do better against left-handed pitchers. This is not required by the rules of baseball; it is just something that happens. I propose to call these "third-personal fallout facts from institutional facts", or more briefly, "fallouts" from institutional facts. They are "third-personal," because they need not be known by participants in the institution. They can be stated from a thirdperson, anthropological, point of view. They carry no additional deontology, and so no new power relations are created by fallouts. (Searle, 2010, p. 117)

As Searle notes, systematic fallouts are typically described by economic theories:

In economics the ground-floor facts are in general intentionality-relative. For example, so and so bought and sold such goods. But the facts reported by economists are typically intentionality-independent. For example, the Great Depression began in 1929. (Searle, 2010, p. 117)

Concepts of this kind are also relevant for law, however, and for the different perspectives that can be adopted in the legal domain. Consider, again, the example of norm-enacting procedures in a Parliament, for which we have already argued the relevance of metainstitutional concepts. Here also para-institutional concepts can emerge, both praxeological and idiomatical. One example is the concept of "parliamentary obstructionism", or "filibustering". With these concepts, we denote typical parliamentary strategies that can be carried out while instantiating institutional rule-constituted concepts. During filibuster, we follow all the rule-constituted procedures set forth in the chambers' regulations, but we do so as part of an overall strategy, like in the case of attacks or defences in chess: Hence, this is

12 Cf. also (Thomasson, 2003, p. 275-6), (Andersson, 2007, p. 105-26). 
a typical case of praxeological para-institutional concept subordinate to the institutional concepts of a given legal system's norm-enacting procedures. ${ }^{13}$ In some situations, filibustering can give place to "legislative gridlocks", namely, situations in which actual parliamentary practice cannot have any significant normative outcome because no party has a filibuster-proof majority. This, too, is a non-rule-constituted para-institutional concept, because the constitutive rules of parliamentary procedures do not create the concept but are necessary to create the institution for which a legislative gridlock can happen. However, differently from the case of "filibustering", with "legislative gridlock" we denote a typical state of affairs or situation produced by parliamentary practices and not a sort of parliamentary action or strategy: Hence, this an idiomatical, and not praxeological, parainstitutional concept.

What kind of perspective we adopt when using concepts like "filibustering" and "legislative gridlocks" in connection with the practice of norm-enactment in a given legal system? Given the subordinate status of these concepts, in this case we have to do with second-order perspectives, namely, perspectives consisting in statements that already take for granted the instantiation and normative outcomes of institutional acts and facts as they emerge from a purely structural perspective, as well as the overall teleological and axiological structure of the institution as it emerges from meta-institutional concepts. That of praxeological para-institutional concepts is a strategic perspective, as when members of the House of Commons decide to practice filibustering to hinder the enactment of a given statute. From a strategic point of view, the main focus is not on the correct instantiation or performance of a given legal fact or act, as in the case of a structural perspective, nor on the fundamental objectives and values of legal practices, as with the teleological and axiological perspectives, but rather on the participants' attempt to obtain results in the most effective way. The key concept here is indeed efficiency: The relevant question is not that some

13 One could object here that "filibustering", considered as a concept relevant for law, seems to be more general than "King's Indian Attack" in chess. I can certainly concede this point, but two things are worth noting in this connection. On the one hand, one could specify forms of filibuster typical of different legal systems, just as there are different forms of attack typical of chess. On the other hand, the concept of "attack", too, is a para-institutional concept of chess, even though chess shares it with other games (but not all: in several competitive card games, for example, you cannot strictly speaking "attack"). 
normative consequences derive from formalized procedures, but rather how I can obtain those consequences (or make it so that others do not obtain them) while minimizing my effort.

Idiomatical para-institutional concepts, instead, are typically used by someone who describes the features of a given legal framework not structurally, that is, taking into account its constitutive rules only, but practically, namely, describing how that framework turns out to be when actually practiced. This, too, is a peculiar perspective that can be taken over legal practices: a sort of sociological perspective from which the features of legal systems as it is "in reality", so to say, are conceptualized and described. And here, too, the structural features of an institutional framework are already given for granted: What matters is not what constitutive rules state but rather what happens in practice when those rules are followed - the expected or unexpected outcomes of that practice.

While a strategic perspective is taken by participants, a sociological perspective is taken by observers. This does not mean, however, that participants who act strategically cannot make good use of a sociological perspective: The peculiar outcomes of a given legal practice are essential when evaluating what to do from a strategic point of view. If for, example, I know that legislative gridlocks can happen in a given legal setting, and how they typically happen, I can use this information to act strategically toward the goal of new elections. And, on the other hand, a good sociological description of how a given legal framework actually works in practice must be able to take into account the strategic reasoning of all actors. Thus, the two perspectives that typically involve para-institutional concepts—strategical and sociological-are intertwined in a peculiar way, as in the case of the teleological and axiological perspectives that involve meta-institutional concepts. However, while the connection between teleological and axiological considerations depend on the fact that both perspectives had to do with the concept of a legal practice in general, the connection between strategic and sociological perspectives stems from the fact that both consider that practice as it unfolds in reality - in action, so to say, and not only with regard to its concept (at least as far as it is possible to distinguish between the two).

Again as in the case of theological and axiological perspectives, strategic and sociological perspectives can have an impact on structural considerations. For example, one could want to change the structural features of a given norm-enacting process if he finds that some kind of strategy can be abused within the existing structural framework or if he wants to avoid a 
peculiar feature of the framework's actual functioning as it has been ascertained sociologically. And, in extreme situations, phenomena that emerge from a sociological perspective and that have to do with the actual practice of a given legal institution can result in the death of that institution, particularly where those phenomena represent outcomes that are unacceptable or unbearable for the legal system as a whole (as for reasons of efficiency). This influence of strategic and sociological considerations on institutional structures can be striking if one takes into account the subordinate logical character of para-institutional concepts with respect to institutional concepts. Such an influence shows, however, that the relations of logical dependency holding among perspectives on law do not necessarily correspond to different degrees of importance.

Finally, something should be said on the relation between the sociological perspective discussed here and the social dimension of the teleological perspective discussed above. Typically, peculiar features of a given institutional practice as they emerge from a sociological dimension can be evaluated as defects or strengths in terms of a given social teleology. One could, for example, say that the frequent occurrence of legislative gridlocks in the Italian parliamentary practice has been a defect when evaluated from the typical social purpose of that kind of practice. This makes it clear that there is a crucial difference between what I have called a socio-teleological perspective and a sociological perspective: The first is an evaluative perspective from which the institution is evaluated in terms of its efficiency in fulfilling a given social function, while the second is a descriptive perspective from which some peculiar features of the actual practice corresponding to that institution are identified. Very often the two perspectives are intertwined in sociological (and thus also legal-sociological) research.

\section{Back to Hart's External/Internal Distinction}

Let me come back now to the question that I have addressed at the beginning of this paper, namely, Hart's distinction between an internal and external point of view as a means to explain the meaning of normative vocabulary and the corresponding conceptual structure. What is the relation between Hart's internal and external points of view and the structural, teleological (both normative and social), axiological, strategic and sociological perspectives 
so far discussed? Is there a distinctive advantage in assuming the second, fivefold distinction over the first one? And would it be fruitful to merge the two distinctions?

Let me summarize Hart's argument again and then explain how my fivefold distinction among kinds of concepts and perspectives can have a bearing on this subject matter. Some of these theses have become so mainstream in contemporary Anglo American jurisprudence that I feel I should apologize for reconstructing again such a well-known argument. According to Hart, the peculiar feature of the internal point of view is that, in this view, rules are conceived as normative reasons for action and not mere regularities, and thus give place to what he has famously called a "reflective critical attitude". This reflective attitude is in its own turn connected with a certain kind of linguistic behaviour on the part of officials engaged in the legal practice. In those cases in which a legal system consists of primary rules only (and is therefore quite primitive), that linguistic behaviour typically consists of taking the rules as a basis for criticisms and justifying both demands for conformity and sanction in case of deviance. If, instead, the legal system include secondary rules (and hence, in Hart's view, is a developed legal system), the linguistic behaviour connected with the internal point of view calls into question a whole lot of new terms and new concepts, a normative vocabulary and conceptual structure which is necessary to understand in order to explain the practice of law. Hart provides several examples of these terms and concepts. Consider again a portion of the passage drawn from The Concept of Law which has been already quoted at the beginning of this paper:

With this extension comes a whole set of new concepts and they demand a reference to the internal point of view for their analysis. These include the notions of legislation, jurisdiction, validity, and, generally, of legal powers, private and public. (Hart 2012 (1st ed. 1961), 98-9; italics added.)

"Legislation", “jurisdiction", "validity", and "powers", are therefore among the normative concepts that, according to Hart, require an explanation by means of the internal point of view. Other examples can be found in his celebrated essay Definition and Theory in Jurisprudence:

[L]et us take words like 'right' or 'duty' or the names of corporations, not alone but in examples of typical contexts where these words are at work. Consider them when used in statements made on a particular occasion by a judge or an ordinary lawyer. They will be statements 
such as 'A has a right to be paid $£ 10$ by B.'; 'A is under a duty to fence off his machinery.'; 'A \& Company, Ltd. have a contract with B.' (Hart 1983, 27; italics added)

Hence, also the terms right, duty, contract, and the names of corporations (as well as the corresponding general concept of "corporation") seem to be part of the normative vocabulary and conceptual structure that are inherently internal in Hart's view.

Here our fivefold distinction among kinds of concepts comes up: Among Hart's examples of internal concepts, in fact, some are institutional whereas others are metainstitutional concepts. Consider again the case of "validity". As we have seen in Section 3 above, different kinds of sources of law in the Italian legal system have an institutional concept ultimately defined in terms of their conditions of validity, and hence validity is a meta-institutional concept with regard to them. Hence, there is a relation of logical subordination between the concept of validity and that, for example, of legge in the Italian legal system. Now, considering the other examples of internal concept made by Hart, it seems to me that the same relation of logical subordination holds between corporations and contracts, on the one hand, and rights, duties, and powers on the other hand: The former are institutional, the latter meta-institutional concepts. Corporations and contracts are entities and procedures created and defined (constituted) by the rules of a legal system in terms of the rights, duties, and powers they entail. Their conceptual connection with these last is among the necessary conditions that make them legal concepts in the first place, because "rights", "duties", and "powers", like "validity", are not concepts constituted by the rules of a given legal system but rather define the general framework (the "broader social practice", as I have said in Section 3) in which those constitutive rules find their role as legal rules. Those concepts define the grammar of law, not of the British legal system, and thus are part of the conceptual background within which the constitutive rules of the British legal system can, for example, create and define the concept of a corporation. This means that the distinction between institutional and meta-institutional concepts seems able to capture a fundamental logical distinction among Hart's examples of internal concepts.

In this light, it is possible to draw the conclusion that, just as the distinction between institutional and meta-institutional concepts seems to specify Hart's examples of internal concepts, the corresponding distinction between structural, teleological, and axiological perspectives can be taken to specify in greater focus the Hartian concept of internal point of view. In fact, the kind of normative attitude that Hart attributes to agents acting within the 
internal point of view can address either the structural features of a given legal system, its internal teleological framework, or its axiological evaluation. For example, a statement like (a) "with age of majority a person acquires full legal capacity", that spells out the normative consequences entailed by the institutional concept of age of majority and hence is formulated within a strictly structural perspective, is an internal statement in Hart's sense. But if I deal with the concept of validity and say, for example, (b) "if you want that contract (or statute, or legge) to be valid, you will have to fulfil this and this condition", I make another kind of internal statement that is connected with a teleological (normative) perspective. Further, despite Hart's well-known thesis about the separation between law and morality, at least some evaluations made from an axiological perspective, such as $(c)$ "This is an unfair ruling", could also be accepted by Hart as internal in the legal sense-and if, instead, we assume a post-Hartian, constitutionalist approach to the internal point of view, such as that of Alexy discussed in Section 3, the degree of coincidence between axiological and internal is certainly increased.

Hence, the distinction between structural, teleological, and axiological perspectives entails a distinction between three different kinds of internal statements that Hart did not formulate but that can perhaps be used to fruitfully complement his view. It is important to note, however, that those perspectives are not necessarily internal. Just like seemingly internal statements can be made from a point of view which is not genuinely internal (as in the case of Raz's “detached” statements: but see (Toh, 2007, p. 414) for an internal reading of these statements), the same holds for statements made from a structural and teleological perspective. I can perfectly describe, for example, the structural and teleological features of a legal system from a "detached" stance in Raz's sense, and even a "detached" use of axiological evaluations is not impossible: For example, I can use a given constitutional vocabulary, in which axiological meta-institutional and institutional concepts are inevitably intertwined, without necessarily embracing the values embodied in that constitution.

The possibility of a "detached" use of internal statements implies that the fivefold distinction among structural, teleological, axiological, strategic, and sociological perspectives has an advantage over the twofold one between internal and external points of view. In fact, while the occurrence of normative internal concepts in a statement cannot rule the possibility that the point of view is not internal but "detached", the connection between the kinds of concepts and the perspectives discussed in this paper is much stricter. Statements 
such as $(a),(b)$, and $(c)$ can be either internal or "detached", depending on the point of view of the speaker, but they are in any case structural, teleological, and axiological statements because they have as their main subject things denoted by institutional and meta-institutional (teleological and axiological) concepts. In this case, the occurrence of those concepts seems to be a quasi-sufficient condition for the adoption of the corresponding perspective, while Raz's argument on "detached" statements shows that it is not so when it comes to normative concepts and the internal point of view. Hence, Raz's objection seems weaker when directed against the correspondence between kinds of concepts and perspectives argued for here than in the case of the internal/external distinction.

I have said in Section 1 that Hart's distinction between points of view has difficulties not only in including certain kinds of statements, as in the case of "detached" statements, but also in excluding others, as in the case of Perry's reading of Holmes's "bad man's" perspective as an internal perspective. Here, too, it seems to me that my distinction between perspectives can be helpful. The perspective of the "bad man", who according to Perry uses rules as prudential reasons, is a kind of strategic perspective; but, just like the structural, teleological, and axiological, a strategic perspective can be either internal or external, depending on the normative commitment of the agent. I do not agree with Perry that, by simply considering rules as prudential reasons, an agent places himself within the internal point of view in Hart's sense: It seems to me that, when Hart speaks of rules as reasons in the internal point of view, he intends normative, strong reasons, not simply prudential ones. Hence, the "bad man's" perspective as discussed by Perry is a case of external strategic perspective in which an agent reconstructs the normative beliefs of a given community (and thus adopt a "moderate" external point of view in Hart's sense) and then acts strategically on the basis of the behavioural predictions he is able to infer from those beliefs. But an internal strategic perspective is also possible, in which an agent accepts the normative and axiological structure of the legal system and simply considers how to behave more effectively in the context of this structure. I can, for example, accept current regulations in the Italian taxation and still act strategically in order to pay the least possible amount of money. Finally, also the sociological perspective seems to allow for both an external and an internal reading: Consider, in this regard, the case of "legislative gridlocks" discussed in Section 4. I can use my knowledge regarding legislative gridlocks in the Italian legal system either externally, as an observer who simply records the fact that parliamentary practice in 
Italy often leads to paralysis, or internally, as a politician who is committed with the Italian constitutional structure, knows how gridlocks of this kind typically occur, and hence acts to avoid them (or even to purposely incur into them in case he believes, for example, that an unconstitutional statute should not be passed by the Parliament and that the gridlock is the only effective way to obtain this result).

\section{Conclusion}

What conclusion, then, can we draw from this discussion of Hart's distinction between internal and external point of view in the light of that among structural, teleological, axiological, strategic and sociological perspectives? In general, it seems that the internal/external distinction can indeed act and be fruitful in the explanation of legal practices, as Hart maintained, but only as a second layer of explanation after the fivefold distinction argued for here. Hence, when dealing with statements and inferences made by agents engaged in a legal practice, we should ask first what is the perspective in which these statements and inferences are made-whether a purely structural one, or a broader teleological and axiological, or a more concrete strategic and sociological perspective-and then ask whether they adopt that perspective internally or externally.

To explain this point a little bit further, it is useful to present the relation among the five perspectives and Hart's internal/external distinction in dynamic terms, namely, as a process of progressive broadening and layering of an agent's point of view over the law. I will start with a purely structural perspective, in which the agent considers one or more institutional concepts in terms of their conditions of performance and normative import as constituted by the rules of a given legal system. This is the basic perspective, that in which we are able to recognize what exists and happens in the legal reality: The only thing that matters here is whether a given legal act or fact has been correctly instantiated and what are its normative outcomes. However, as argued above, an accurate description of this reality cannot take into account only rule-constituted concepts and their instantiation: The structural perspective must be complemented with others. The dynamics by which we move from a structural perspective to an axiological and teleological one, or to a strategic and sociological one, is different. The teleological and axiological perspectives conceptually broaden the scope of the structural one, placing the structure of institutional rule-constituted concepts in its wider 
context, namely, within the concept of a general and shared legal (social) practice that comes with its purposes and values. Instead, the strategic and sociological perspectives do not broaden the structural perspective on a conceptual level but rather add another layer of considerations to it, by seeing how the structural web of rule-constituted concepts turns out to be when actually practiced in a given social context. Thus, if we start from a structural perspective on legal phenomena, it is possible to imagine two different operations by which to enrich it: conceptual broadening and practical focus.

Then comes Hart's distinction between an internal and an external point of view. This is a distinction having to do with the agent's attitude, while nothing the agent has done up to this point necessarily implied a specific normative disposition on his or her part. A new dynamics emerges here, one which calls into play the subjective dimension, namely how the agent considers and is disposed to treat-whether normatively or descriptively-those normative structures and practical features he has ascertained by assuming the other perspectives. We have to do here with a reflective focus on the subjective attitude of the agent, distinct from the other two operations of conceptual broadening and practical focus. Figure 1 below summarizes graphically the three different dynamics among perspectives and points of view over the law.

One could wonder whether this complicated analysis of the dynamics among legal perspectives is in the end useful for an explanation of legal practices, apart from its being able to specify and perhaps improve Hart's model. The main reason why I think it is useful is that it improves our capability to account for different normative attitudes, over and above the simple acceptance/non-acceptance dichotomy that grounds Hart's distinction between internal and external point of view. Consider again, in this regard, the case of a politician engaged with parliamentary practices: Indeed, it is advisable to reflect a little bit more on the role of senators and deputies in the light of Hart's model. Hopefully, in most cases, these are agents who strongly embrace the normative structures stemming from a given constitution and the corresponding legal system: They can even be part of the process which produces a new constitution or constitutional reform, thus becoming the very authors behind those normative structures. However, it would be naïve to conceive senators and deputies in a parliament simply as abiding norm followers who do no want to see, even less exploit, the peculiar features and possible shortcomings of parliamentary regulations. They must fight hard battles in a parliament, with all the instruments that the regulations give 
them, possibly also exploiting some of the gaps that those regulations leave open. This mean that they must be good strategists, and even good sociologists at least in respect to their honourable colleagues.

While Hart's internal/external distinction is directly intended to explain the point of view of judges, I am not sure whether it can provide a good explanation of the point of view of deputies and senators. In this case, more "shades" are needed, and perhaps the kinds of perspectives I have presented in this paper can improve our capability to provide such shades.

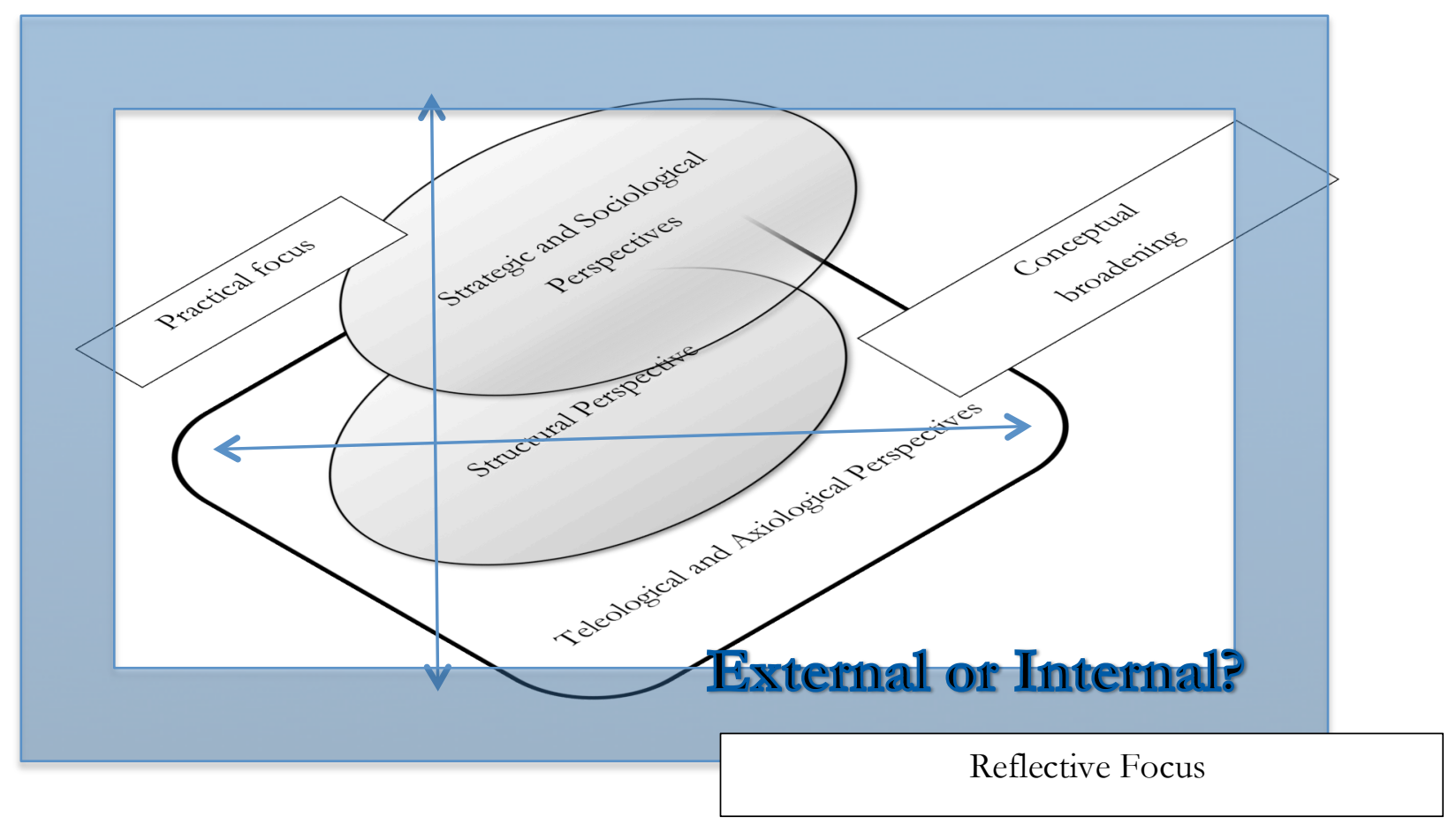

Figure 1 - Dynamics among Perspectives

Corrado Roversi

CIRSFID - University of Bologna - Faculty of Law

Via Galliera 3

40121 Bologna 
ITALY

$+39(0) 51277203$

corrado.roversi@unibo.it

\section{References}

Alexy, R. (2002). The Argument from Injustice. A Reply to Legal Positivism. Oxford: Clarendon Press.

Andersson, A. (2007). Power and Social Ontology. Malmö: Bokbox Publications.

Conte, A. G. (1995 (1st ed. 1993)). Deontica wittgensteiniana. In A. G. Conte, Filosofia del linguaggio normativo. II. Studi 1982-1994 (pp. 517-61). Torino: Giappichelli.

Conte, A. G. (2003). Filosofia del baro. Rivista internarionale di filosofia del diritto , 80, 679-747.

Hart, H. L. (1983). Definition and Theory in Jurisprudence. In H. L. Hart, Essays in Jurisprudence and Philosophy (pp. 21-48). Oxford: Clarendon.

Hart, H. L. (2012 (1 st ed. 1961)). The Concept of Law. 3rd Edition. Oxford: Clarendon.

Hindriks, F. A. (2009). Constitutive Rules, Language, and Ontology. Erkenntnis, 71, 253-75.

Hindriks, F. A. (2005). Rules \& Institutions. Alblasserdam: Haveka BV.

Kelsen, H. (1992 (1934)). Introduction to the Problems of Legal Theory. Oxford: Clarendon Press.

Kolnai, A. (1966). Games and Aims. Proceedings of the Aristotelian Society, 56, 103-28.

Lorini, G. (2003). Cinque livelli di descrizione di un atto istituzionale. In P. Di Lucia (Ed.), Ontologia sociale. Potere deontico e regole costitutive (pp. 299-308). Macerata: Quodlibet.

Lorini, G. (2000). Dimensioni giuridiche dell'istituzionale. Padova: Cedam.

MacCormick, N. (1986). Law as Institutional Fact. In N. MacCormick, \& O. Weinberger (Eds.), An Institutional Theory of Law (pp. 49-76). Dordrecht: Kluwer.

MacCormick, N. (1998). Norms, Institutions, and Institutional Facts. Law and Philosophy , 17, $310-45$.

Marmor, A. (2007). Deep Conventions. Philosophy and Phenomenological Research , 586-610.

Marmor, A. (2009). Social Conventions: From Language to Law. Princeton: Princeton University Press. 
Miller, D. (1981). Constitutive Rules and Essential Rules. Philosophical Studies, 39, 183-97.

Perry, S. (2000). Holmes versus Hart: The Bad Man in Legal Theory. In S. J. Burton (Ed.), The Path of the Law and Its Influence. The Legacy of Oliver Wendell Holmes, Jr. (pp. 158-96). Cambridge: Cambridge University Press.

Raz, J. (1999 (1975)). Practical Reason and Norms. Oxford: Oxford University Press.

Raz, J. (1980 (1st ed. 1970))). The Concept of a Legal System. 2nd Edition. Oxford: Clarendon.

Ross, A. (1957 (1951)). Tû-Tû. Harvard Law Review (70), 812-825.

Rotolo, A., \& Roversi, C. (2013). Constitutive Rules and Coherence in Legal Argumentation: The Case of Extensive and Restrictive Interpretation. In Legal Argumentation Theory: Cross-disciplinary Perspectives (pp. 163-88). Berlin: Springer.

Roversi, C. (2012). Costituire. Uno studio di ontologia giuridica. Torino: Giappichelli.

Schwyzer, H. (1969). Rules and Practices. The Philosophical Review, 78, 451-67.

Searle, J. R. (2010). Making the Social World: The Structure of Human Civilization. Oxford: Oxford University Press.

Searle, J. R. (1969). Speech Acts. Cambridge: Cambridge University Press.

Searle, J. R. (1996 (1995)). The Construction of Social Reality. London: Penguin.

Suits, B. (1978). The Grasshopper. Toronto: Toronto University Press.

Thomasson, A. (2003). Foundations for a Social Ontology. Protosociology , 18-19, 269-90.

Toh, K. (2007). Raz on Detachment, Acceptance and Describability. Oxford Journal of Legal Studies, 27 (3), 403-27. 